\title{
PSYCHE
}

Vol. 75

December, 1968

No. 4

\section{MEGASECOPTEROUS NYMPHS IN PENNSYLVANIAN CONCRETIONS FROM ILLINOIS}

By F. M. Carpenter, Harvard University

AND

Eugene S. Richardson, Jr., Field Museum of Natural History

Recognition of immature stages of insects belonging to extinct orders is peculiarly difficult. We have no definite knowledge of the immature forms of any extinct order except the Protorthoptera. The few specimens of nymphs which have been placed in the Palaeodictyoptera almost certainly belong elsewhere; at any rate, they do not show features which justify their reference to that order (Carpenter, 1948). ${ }^{1}$ Possible nymphal forms of the Megasecoptera have been described by $\mathrm{Handlirsch}$ and by Bolton. Lameereites curvipennis Handlirsch, from the vicinity of Mazon Creek, Illinois, was based on a single specimen consisting of four "wing cases" (Handlirsch, I9I I, p. 374). The homonomous nature of the wing cases, their shape and venation led Handlirsch to believe that they were Megasecoptera, although he did not attempt a family assignment. No body structures were mentioned or figured but he was of the opinion that the position of the wing cases, "on the sides of the thorax ... strongly spread out" was a primitive one. Several isolated nymphal wings from British Upper Carboniferous strata were described by Bolton (I92I) as belonging to the Brodiidae, which he considered to be Palaeodictyoptera, though most workers have placed them in the Megasecoptera (see Carpenter, 1967).

There has at last been collected, in an ironstone nodule from the Francis Creek Shale of Illinois, a magnificently preserved nymph

\footnotetext{
${ }^{1}$ Since the publication of this 1948 paper, one additional Carboniferous nymph (Rochdalia parkeri Woodward) has been referred to the Palaeodictyoptera (Rolfe, 1967). I have not seen this fossil, but on the basis of the published photographs and the conclusions reached in the present paper I seriously doubt the correctness of that assignment. F.M.C.
} 
which shows clearly characteristics of certain adult Megasecoptera. The fossil was collected by Mr. Lincoln Douglass of Western Springs, Illinois, and is now in the collection of Mr. David Douglass. It provides the first unquestionable information about the immature stages of the Megasecoptera and in addition furnishes totally unexpected evidence bearing on wing development in primitive paleopterous orders. In our opinion, it is one of the most important fossil insects ever found.

We are indebted to Mr. and Mrs. Douglass and to David Douglass for placing the fossil at our disposal and allowing its preparation and study to be made at both the Field Museum and Harvard University. Satisfactory investigation of fossil insects is difficult at best and can be made only under optimum conditions of preparation and examination. All who are seriously interested in fossil insects and insect evolution are indebted to the Douglass family for their full cooperation and assistance. We are also grateful to Mr. Jerry Herdina of Berwyn, Illinois, and to Helen and Ted Piecko of Chicago for allowing us to study several fossil nymphs which are contained in their collections and which have given us significant information about the development of the nymphs. Finally, we are indebted to Dr. Jarmila Kukalová of Charles University in Prague (but currently at Harvard University) for her careful preparation of the fossils and for her assistance with the illustrations. Financial support of this research is gratefully acknowledged to the NSF by the senior author (grant no. GB 7308) and by the junior author (grant no. GB 5772). Before describing the new fossil nymph, we include an account of Lameereites curvipennis, based on a study of the type specimen (no. 66, Peabody Museum, Yale University). ${ }^{2}$ Since the Douglass nymph shows many features of the adult Mischopteridae, it is placed in that family. Lameereites, although clearly related to

\footnotetext{
${ }^{2}$ We are indebted to the authorities of the Peabody Museum at Yale University for the loan of this fossil, which was collected at Mazon Creek, Grundy Co., Illinois. This and the other megasecopterous nymphs discussed herein are from the Middle Pennsylvanian (Westphalian C) Francis Creek Shale of the Carbondale Formation.
}

Plate 25. Figures 1-3, Lameereites curvipennis Handlirsch, holotype. Fig. 1, drawing of fore wing. Fig. 2, drawing of head and beak. Fig. 3, drawing of antenna. Length of wing, $16 \mathrm{~mm}$.; of antenna, $5.7 \mathrm{~mm}$.

Figures 4 and 5. Mischoptera douglassi Carpenter \& Richardson, n.sp., holotype. Fig. 4, drawing of fore wing. Fig. 5, drawing of hind wing.

Venational lettering as usual; w, marginal part of wing case; $p$, palpus; c, clypeus. 

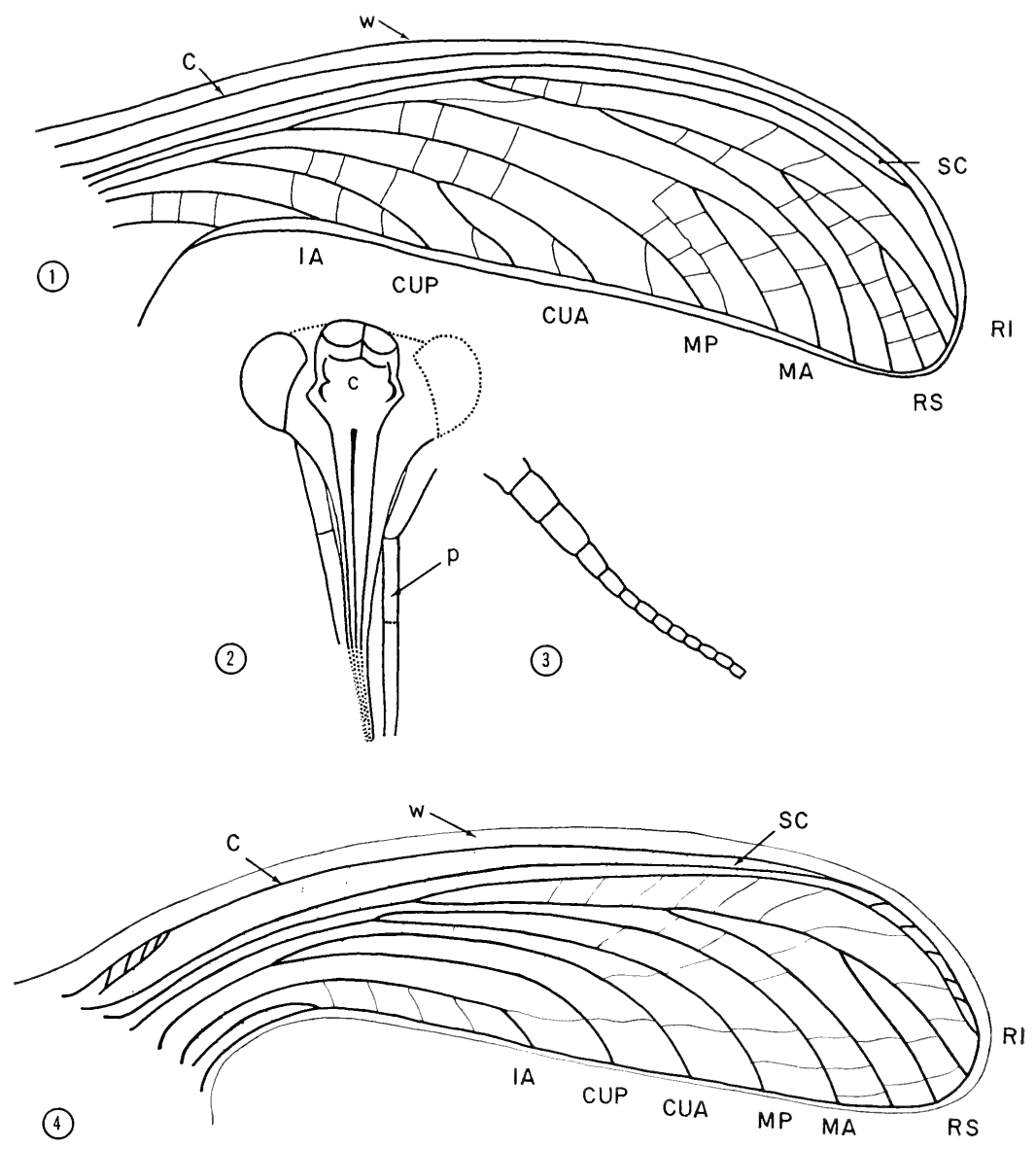

(5)

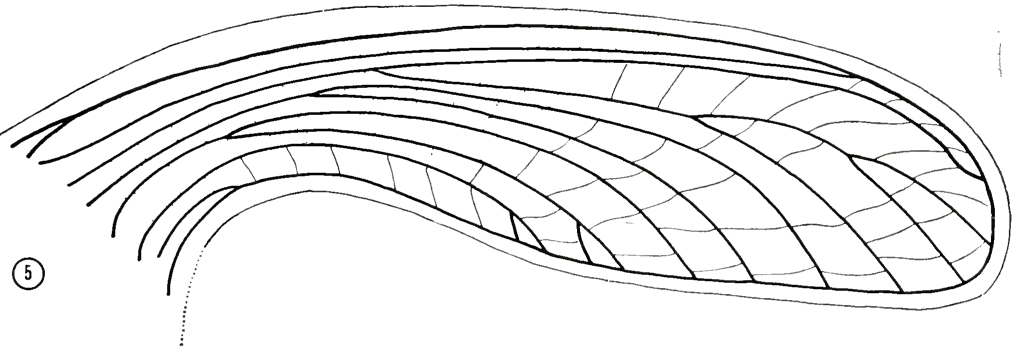

C.arpenter and Richardson - Megasecopterous Nymphs 
it, does not show the same family traits and is consequently included in the Order Megasecoptera, but without family assignment (incertae familiae).

\section{Order Megasecoptera Incertae Familiae}

Lameereites curvipennis Handlirsch

Handlirsch, 1911, Amer. Journ. Sci., 31: 375, fig. 59, 60.

Handlirsch, quite correctly, made no attempt to designate the generic or specific characteristics of this insect. As known to him, the specimen consisted of four nymphal wing pads; however, these are not just "wing cases", as he termed them, but complete wing pads. The application of glycerin or alcohol to the specimen brings out clearly the developing wing within the outer, cuticular case. Handlirsch's drawing shows that he mistook the outer margin of the developing wing for the subcosta. Actually, the venation is clearer than his figure would suggest (Plate 25, fig. I). Sc is distinct and can be followed nearly to the wing apex; $\mathrm{R}_{\mathrm{I}}$ extends even further; $\mathrm{MA}$ is forked, $\mathrm{CuA}$ is branched and both $\mathrm{MP}$ and $\mathrm{CuP}$ are unbranched; there appear to be two short anal veins; MA is remote from Rs, at no place approaching close to it. Cross veins, not shown in Handlirsch's drawing, are discernible with careful examination; they are irregularly arranged and do not form rows in any part of the wing.

Handlirsch's figure correctly represents the position of the four wings in the nodule: the fore and hind wings on one side are separate but on the other side they overlap slightly. As thus arranged they appear to extend from the sides of an invisible thorax and to spread outward, as Handlirsch noted. The complete absence of the thorax in the fossil has obviously introduced some doubt about his conclusions regarding the position of the wing pads; at any rate, no one seems to have given his conclusions the serious consideration they would otherwise have deserved. The new nymphs discussed below show that Handlirsch was correct.

Handlirsch appears to have made no attempt to excavate whatever parts of the insect may have been hidden in the matrix of the rock. Actually, when we first examined the type specimen for the purposes of this study, we could see enough of the head to justify

Plate 26. Mischoptera nigra Brongniart, Upper Carboniferous of France; photograph of specimen in Laboratoire de Paléontologie, Paris, showing antennae, fore legs and thoracic spines. The spines on abdominal tergites are not readily seen in this specimen. 

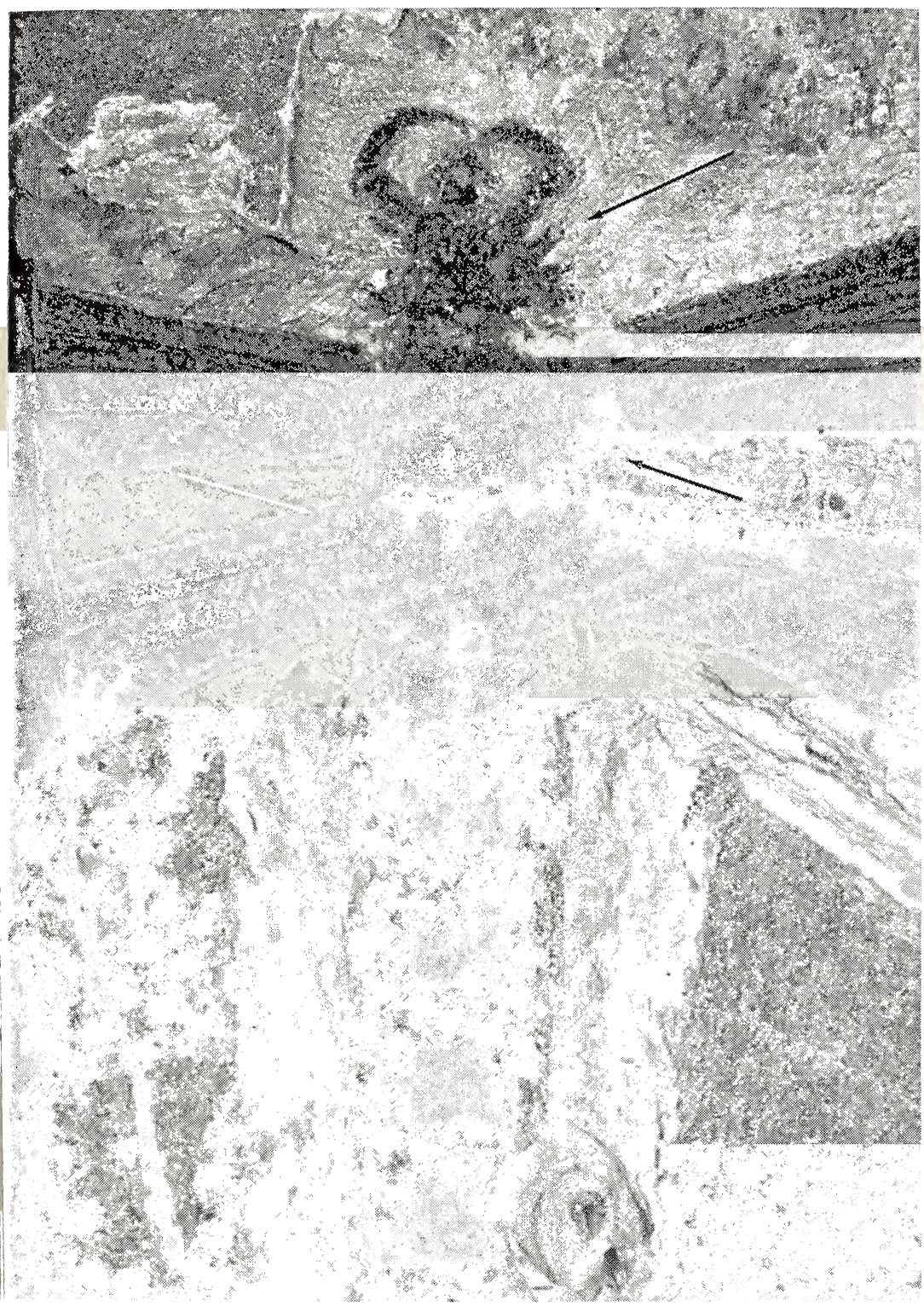

Carpenter and Richardson - Megasecopterous nymphs 
an attempt to uncover more of it. The results were much better than expected: the greater part of the head, the beak and one antenna were excavated. (Plate 25, figs. 2 and 3 ). The head is about $7 \mathrm{~mm}$. anterior to the base of the fore wing pad and the beak extends obliquely into the matrix. The head across the eyes is $4.5 \mathrm{~mm}$; the beak itself from the level of the eyes to its apparent end is $7 \mathrm{~mm}$. long, but it may have been a little longer. On each side of the main part of the beak there seems to be a long segmented palpus, similar to that found in the Palaeodictyoptera; as in the latter, also, the clypeus is swollen and ridged. Although the existence of a beak in the Megasecoptera has been known for several years, this is the first specimen which has given any details of structure. So far as can be seen, it is formed like that of the Dictyoneuridae and other Palaeodictyoptera, though not as long as that in the Eugereonidae. One antenna is visible on the left side of the head of the specimen of Lameereites; this can not be seen under alcohol or glycerin but only under oblique light. Thirteen segments can be distinguished (plate 25, fig. 3), the first three of which are much longer than the others. The antenna is at least $5.7 \mathrm{~mm}$. long but since its distal portion is very faintly preserved, it could be somewhat longer.

The most significant feature of Lameereites that has been revealed in the course of this study is the presence of the beak. This, along with the wing venation, establishes beyond doubt its relationship with the Megasecoptera, although not enough details of structure are known to associate it with any one family. However, the wide space between MA and Rs and the absence of rows of cross veins eliminate the Mischopteridae and related families.

The nymph in the Douglass collection is much better preserved than the type of Lameereites, showing the head, beak, antennae, wing pads and many details of the thorax and abdomen. All of these structures turn out to be close to those of the adult Mischopteridae, which seems the most appropriate assignment for the nymph at this time. Of the two known genera of Mischopteridae, Mischoptera and Psilothorax, the former is obviously closer. Since establishment of a separate genus for the nymph seems inadvisable, there being no other nymphs for comparison, it is placed in the genus Mischoptera. Although the family Mischopteridae is otherwise known only from the Upper Carboniferous (Stephanian) of Commentry, France, its presence in the somewhat older Illinois nodules is not surprising; evidence for close relationship between the Mazon Creek and Commentry insect faunas has already been noted (Carpenter, 1967). 


\section{Family Mischopteridae Handlirsch, 1906}

The wings of the adult mischopterids were alike in size, shape and venation; they were distinctly narrowed basally (text-figure $\mathrm{I}$ ); $\mathrm{R}_{\mathrm{I}}$ extended to the apex of the wing, with Sc terminating just before the apex; Rs had three terminal branches; MA anastomosed for a very short distance with $\mathrm{Rs}$, near the origin of the latter; $\mathrm{CuA}$ was independent of MP. The cross veins were regularly arranged and formed two or three definite rows along the outer margin of the wing. The prothorax was short and usually possessed strong lateral projections; the meso- and metathorax have short, stout spines (Plate 26) ; the antennae were relatively short and stout basally, the number of segments unknown; the fore legs were very short, the other two pairs of legs unknown. The abdomen was long and slender, terminating in very long cerci, fully twice as long as the abdomen; the tergites had a series of short spines or projections along their posterior margins.

\section{Mischoptera Brongniart}

Mischoptera Brongniart, 1894, Recherch. Hist. Ins. Foss. 293; Carpenter, 1951, Journ. Paleont. 25: 340 .

This genus is known from ten adult specimens, representing a single species, in the Commentry Shales of France.

\section{Mischoptera douglassi, n. sp.}

\section{Plate 24; Plate 25, figs. $4 \&$ 5; Plate 27; Plate 28.}

Text-figure 2.

This species is based on a single specimen of a nearly complete nymph with the following dimensions: length of body from head to the end of abdomen, $53 \mathrm{~mm}$; width of abdomen at 6th segment, $5 \mathrm{~mm}$; length of antennae, $4 \mathrm{~mm}$. as preserved; length of fore wing, $13.5 \mathrm{~mm}$; width, $3.5 \mathrm{~mm}$. The specific characteristics of this insect are probably to be found in the nature and arrangement of spines on the thorax and on the abdominal terga and possibly in venational details.

Holotype: No. 39 (obverse and reverse) in the collection of Mr. David Douglass, Western Springs, Illinois; it was found by Mr. Lincoln Douglass in a spoil heap of the abandoned Pit 6 of the Northern Illinois Coal Company, about on the Grundy-Will County line, Illinois. The specimen consists of the two counterparts; the one shown in Plate 24 is herein designated the obverse; the reverse is nearly as complete, lacking only the distal portion of one of the hind wings. As is usually the case with fossil insects, the specimen 
is actually a composite of dorsal and ventral surfaces, each of which is included to some extent on each counterpart. The obverse half seems to have the normal dorsal structures more distinctly preserved than the reverse; it probably represents a view of the inner surface of the dorsal wall, with some of the ventral structures more weakly imprinted. The following is a detailed account of the fossil.

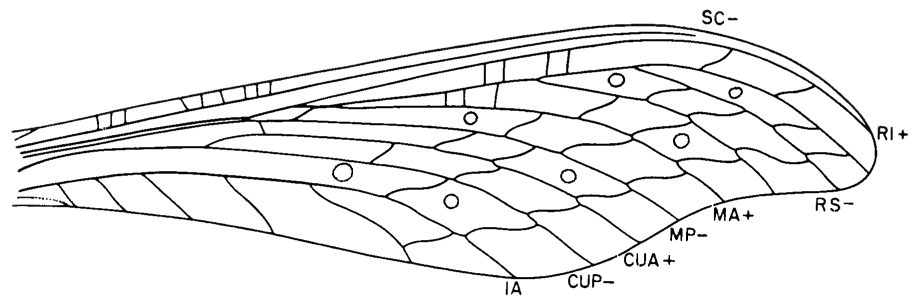

Text-figure 1. Mischoptera nigra Brongniart, Upper Carboniferous of France. Drawing of fore wing, based on specimen in Laboratoire de Paléontologie, Paris.

Wing PADS: These are the most obvious and remarkable structures of the nymph. As shown in the figures, they join the thorax at nearly right angles to the body before being directed obliquely backwards. In none of the existing orders of insects do the nymphal wing pads develop laterally; even in the living paleopterous orders, Ephemeroptera and Odonata, the wings develop as posteriorly projecting pads. The position of the pads in Lameereites would undoubtedly have been the same as in Mischoptera, had the thorax been preserved, and the wing pads of the nymphs in the Herdina and Piecko collections, discussed below, are similarly developed. Examination of the wing pads under alcohol shows clearly the wing itself within the outer, cuticular case. The venation of the fore and hind wing buds is shown in Plate 25, figs. 4 and $5 .^{3}$ The two pairs are surprisingly alike; the hind wing seems to have a somewhat broader basal attachment than the fore. Both pairs of wings have a faint vein or series of veinlets at the base, just below the costal margin; similar structures occur in the wings of some Megasecoptera, as well as in many Palaeodictyoptera. Rs arises just before mid-wing and gives rise to three terminal branches in all four wings; MA approaches closely to Rs just beyond the latter's origin but does not actually come into contact with it; MP diverges from MA just before the origin of Rs and is unbranched in all of the four wings; $\mathrm{Cu}$ forks somewhat

\footnotetext{
${ }^{3}$ This is not tracheation. The veins are preserved as dark lines, showing convex or concave positions.
} 
nearer the base than $\mathrm{M}$; $\mathrm{CuA}$ has a marginal fork in one wing but is unbranched in the others; $\mathrm{CuP}$ is long, extending about to midwing. The degree of development of the anal areas seems to be somewhat different in the four wings but this may be the result of slight distortion of the wing bud; in all wings there seem to be a prominent anal vein and a very short submarginal vein nearer the base. Cross veins can be discerned only faintly and with uncertainty over most of the wing, but in the posterior parts of the wing and along the hind margin, they are more distinct; two or more distinct rows of cross veins are present posteriorly.

Body Structure: head. This is small in comparison to the rest of the body but has conspicuously bulging eyes. The antennae, which are covered with short hair, are preserved in a nearly symmetrical arrangement; the three basal segments are unusually stout, as in the nymph of Lameereites, with the remaining segments (IO or more) much smaller. The head as preserved seems to have been hypognathous, there being no sign of the beak anterior to the procephalon. However, examination of the head under high power shows a somewhat circular area situated between the antennae; its structure and position suggest that it is a cross section of the beak, which apparently extends into the matrix at right angles to the longitudinal axis of the body. The presence of the beak in the specimen of Lameereites, in any event, is sufficient to demonstrate the existence of a beak in the nymph of Mischoptera. Thorax. The prothorax is remarkably similar to that found in the adult of Mischoptera, there being four lateral spines extending for a considerable distance on each side. The meso- and metathoracic structures are more difficult to interpret. Two prominent spines project from each of the segments, near the bases of the wings, the spines projecting slightly beyond the wing margins and giving the impression that the spines arise from the wings. Less well preserved is another spine from each of these thoracic segments, just posterior to the bases of the wings; only the proximal parts of these spines are preserved, but judging from the width of these bases, we infer that the complete spines were longer than the more anterior pair. There is some indication in the fossil that other spines of comparable structure occur along the dorso-lateral portions of the two thoracic segments above the wing bases and vague indications of another row along the pterothorax below the level of the wings; however, the crushed condition of the body prevents identification of these particular spines. The same preservation prevents satisfactory interpretation of the complicated pattern of thoracic structures actually visible in the fossil. The mesothorax seems somewhat the 


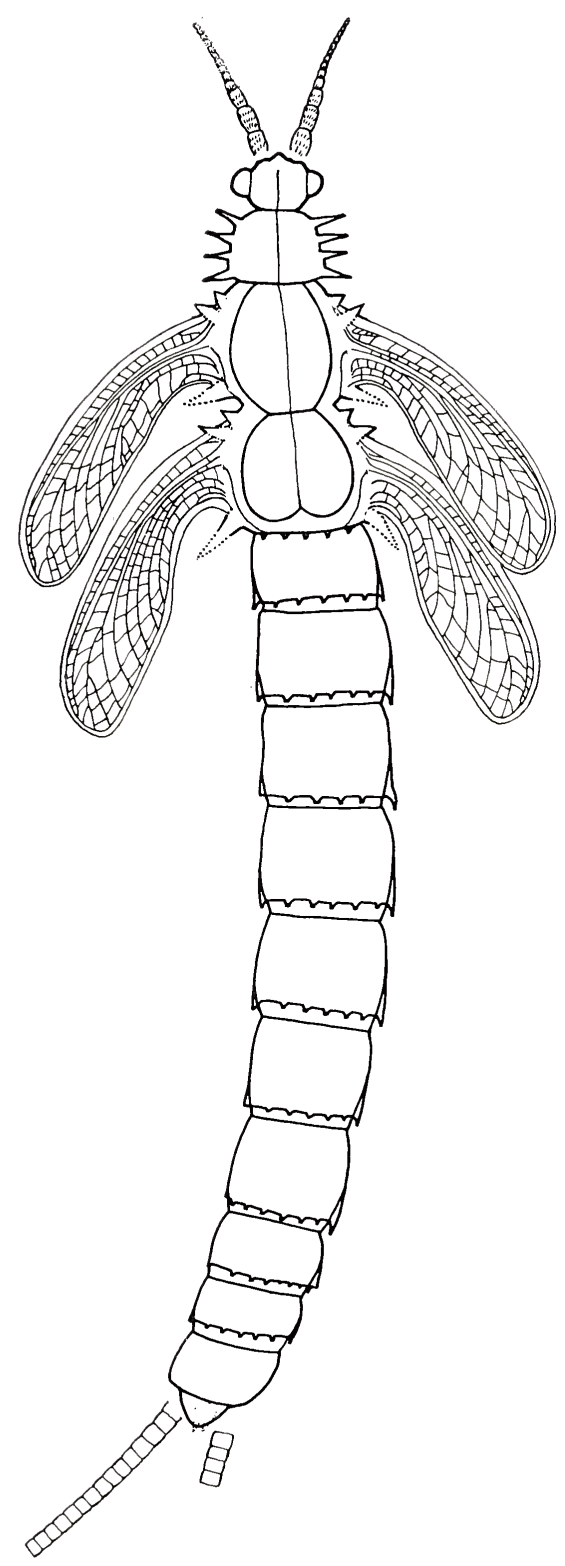

Text-figure 2. Mischoptera douglassi Carpenter \& Richardson, n.sp. Drawing based mainly on obverse of holotype. 


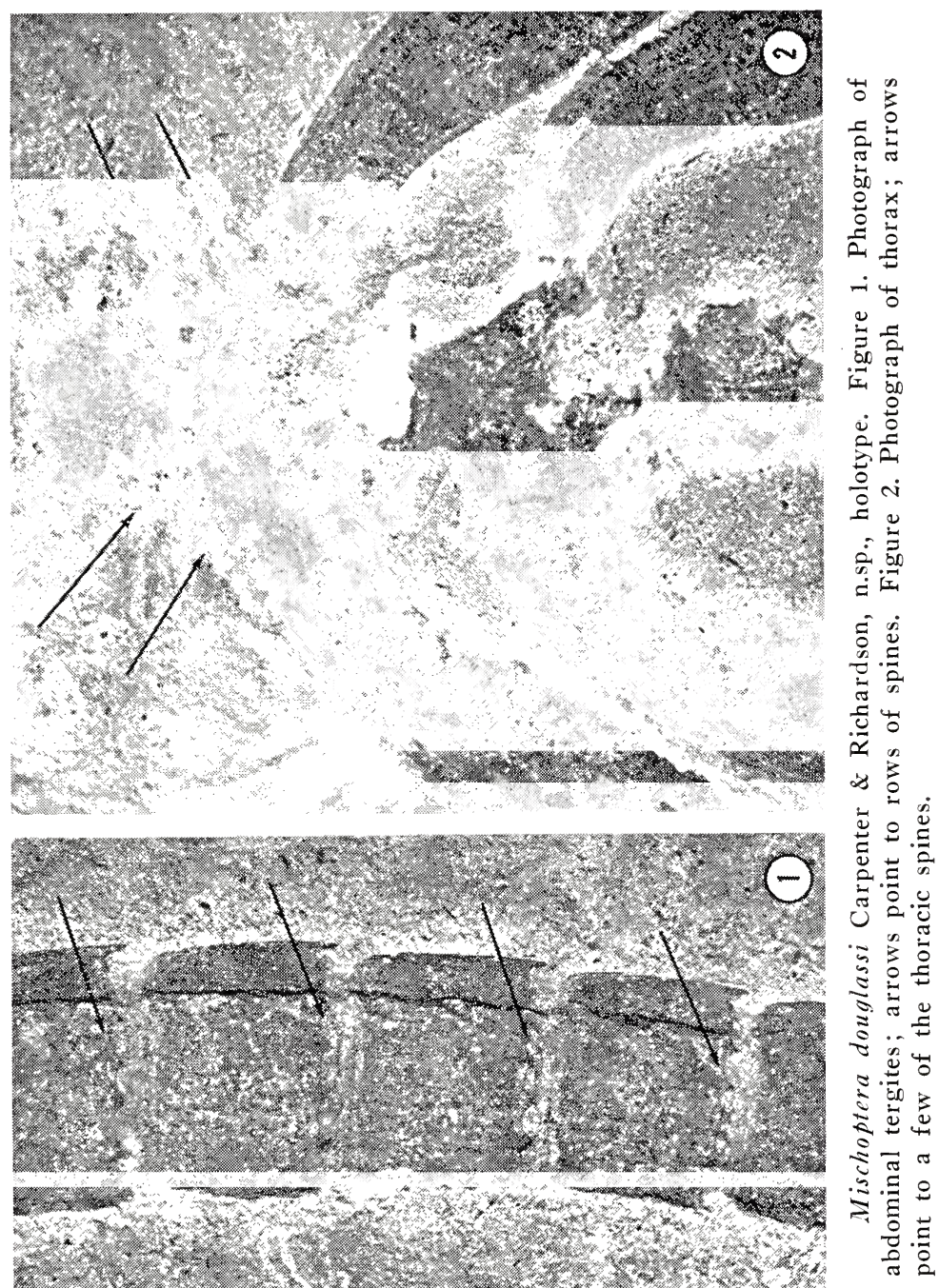


larger and to have a dorsal ridge running along the lateral edges of the notum and between the meso- and metathoracic segments; the metathorax has a similar ridge, which is indented posteriorly. However, not much weight can be given to these vaguely preserved details. There are no clearly preserved legs; this is most unfortunate, since they might show some adaptations for aquatic or terrestrial environments. ${ }^{4}$ It is pertinent to note that in the adults of Mischoptera only the fore pair are known, these being very short and curved under the front of the head (Plate 26). ABDomen. This is long and consists of ten nearly homonomous segments and a shorter, rounded eleventh segment. The hind margins of all of the abdominal tergites, excepting the last two, bear a row of seven stout spines, including the two that appear to be continuous with the lateral edges of the tergites. These spines, which are best studied with the aid of alcohol or glycerin and which can clearly be seen in the photograph (Plate 27, fig. I), are similar to those in the adult Mischoptera but somewhat larger. The abdominal segments also show a series of longitudinal lines somewhat removed from the sides; they are preserved on only one side in the obverse but on both sides in the reverse. They are possibly the ventral margins of tergites, their impressions resulting from the flattening of the abdomen during preservation, or possibly lamellae, like those in mayfly nymphs. However, there is some doubt in our minds about the correct interpretation of the structures along the sides of the abdomen. The cerci, which are covered with hairs and are annulate, are preserved only for a short distance but they were clearly well developed and probably about as long as those of the adults. Superimposed on the tenth abdominal segment is the impression of two small projections; their identity is by no means clear but they probably represent part of developing genital structures. The similarities between douglassi and adult Mischoptera are obvious. The most striking one, of course, is the nature of the thoracic spines, but there are in addition the antennal segmentation, the tergal spines of the abdomen, and the pattern of wing venation. The only distinctive difference is the lack of actual contact between Rs and MA in the nymph, but this is perhaps due to the immature state of the wing.

Two additional specimens of megasecopterous nymphs in the ironstone nodules have also been examined; both were collected near the Will-Kankakee County line (Peabody Coal Company Pit I I). One of these, No. 4I I in the collection of Mr. Jerry Herdina, is a whole

\footnotetext{
${ }^{4}$ One metathoracic leg is vaguely preserved in the Herdina specimen (No. H411).
} 


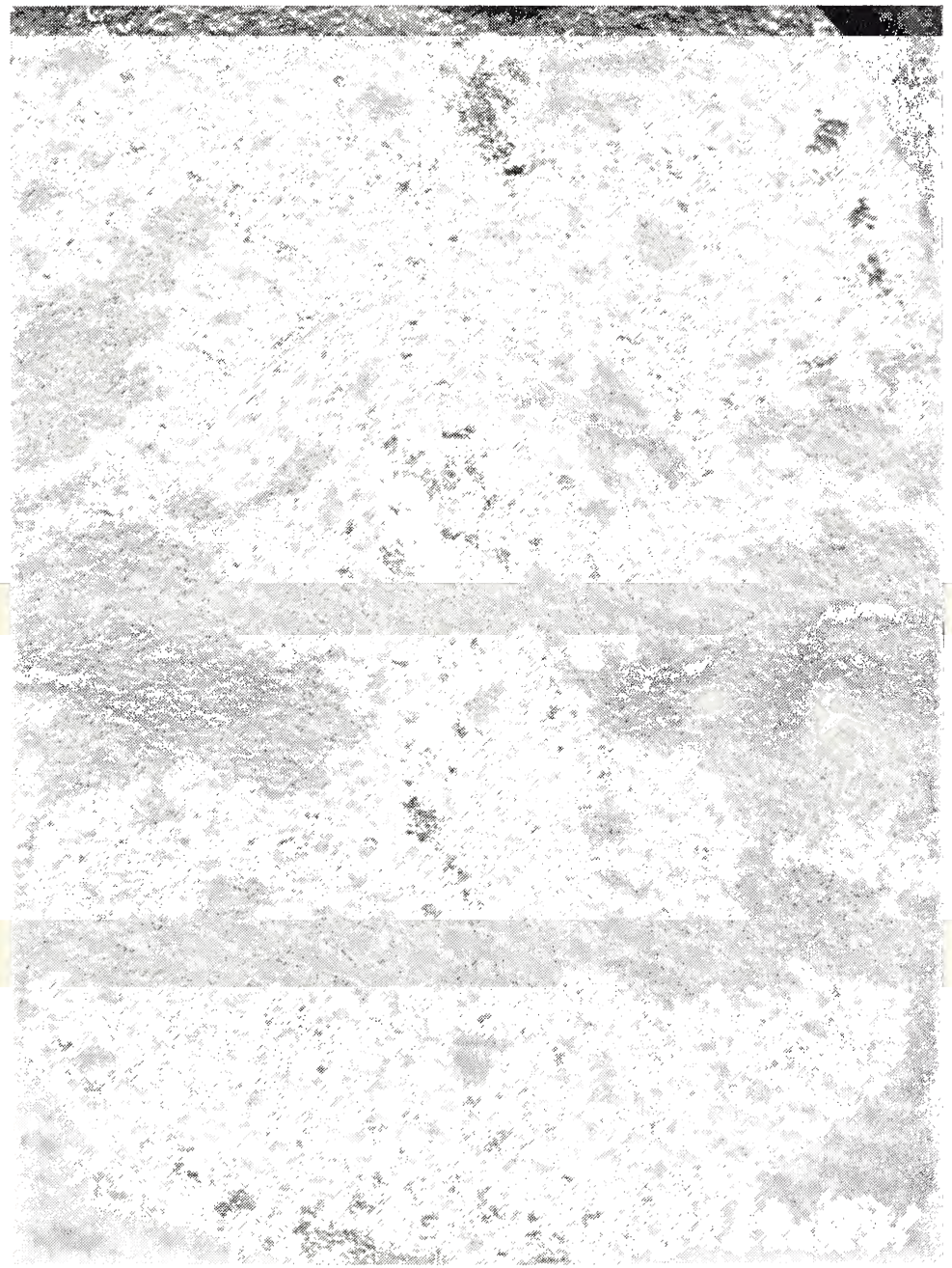

Mischoptera douglassi Carpenter \& Richardson, n.sp. Photograph of young nymph in Herdina collection. Length of fore wing, $7 \mathrm{~mm}$. 
nymph, lacking the last few abdominal segments (Plate 28). It is apparently douglassi but the specimen is much smaller than the type of douglassi and presumably represents a much younger stage, the wing pads being relatively small. In the type of douglassi the length of the wing pads was three times the width of the thorax; in the Herdina specimen the wing pads $(7 \mathrm{~mm}$. long) are only about equal to the width of the thorax. Since the wing pads are in the same position in both nymphs, it is clear that they were independent in the early stages as well as in the more advanced ones. The other megasecopterous nymph (No. HTP 43) is in the collection of Helen and Ted Piecko. This is a very fine specimen, lacking only the end of the abdomen. It is about the same size as the type of douglassi, the fore wing being $15 \mathrm{~mm}$. long, which is about three times the width of the thorax. The wings are in the same position as they are in the other mischopterid nymphs. This specimen is almost certainly douglassi but many structural details remain to be excavated before the identification is certain. At any rate it is clear from these nymphs that the oblique-lateral position of the wing pads is the normal one in this family of Megasecoptera and that the position is constant during the various stages of growth rather than acquired by the older nymphs.

\section{Discussion}

The type of douglassi and the other specimens mentioned above make a major contribution to our understanding of nymphal development of the Megasecoptera. First, it is now clear that the Megasecoptera were exopterygote insects, not endopterygotes, as Lameere, Forbes and others have believed. Second, the oblique-lateral position of the wing pads strongly suggests that the wings in the primitive paleopterous insects developed in that way. ${ }^{5}$ This is supported by the discovery of Permian mayfly nymphs (from Moravia and Oklahoma) in which the wing pads are independent and oblique in all stages (Personal communication, J. Kukalová; see her article in this issue of Psyche). According to this view, the position of the wing pads in the Ephemeroptera and Odonata, fixed longitudinally over the thorax and abdomen, is a secondary one, possibly an adaptation to the

\footnotetext{
${ }^{5}$ Additional evidence is given by the very recent discovery of a whole nymph unquestionably belonging to the Palaeodictyoptera. This fossil was found after the present paper was written, in the course of our search for additional megasecopterous nymphs. The palaeodictyopterous nymph, which has the wings positioned as in the mischopterids, will be described in a later paper.
} 
aquatic environment. Third, the origin and original function of insect wings must now be examined with this new evidence in mind; the possibility of functional movement of the wing pads, for one reason or another, needs to be considered further. Fourth, it is now clear that the beak was as fully developed in the nymphal forms as in the adults of the Megasecoptera and also that the beak in this order was basically like that in the Palaeodictyoptera. It is a virtual certainty that the beaks of the palaeodictyopterous nymphs were also like those of their adults. Since the nymphs of both of these orders almost certainly fed on the same food as the adults and since the adults were clearly terrestrial and aerial, the possibility of the nymphs having been aquatic seems very remote. The complete absence in the mischopterous nymphs of tracheal gills, which are very well developed in the Permian mayfly nymphs (personal communication, J. Kukalová), is another strong indication that the megasecopterous nymphs were not aquatic.

\section{REFERENCES}

Bolton, H.

1921. A Monograph of Fossil Insects of the British Coal Measures. Part 1, pp. 1-80. Palaeontograph. Soc. London.

Brongniart, C.

1893. Recherches pour servir à l'histoire des insectes fossiles des temps primaires. Soc. industr. minérale, Bull., 7: 124-615; also published as Thèse Fac. Sci. Paris, 821, pp. 1-494 (All page and and plate citations in the present paper refer to the Thèse).

Carpenter, F. M.

1948. The Supposed Nymphs of the Palaeodictyoptera. Psyche, 54: 6585.

1951. Studies on Carboniferous Insects from Commentry, France. Part 2. The Order Megasecoptera. Journ. Paleont. 25(3): 336-355.

1967. Studies on North American Carboniferous Insects. 5. Palaeodictyoptera and Megasecoptera from Illinois and Tennessee, with a Discussion of the Order Sypharopteroidea. Psyche, 74: 58-84.

Handlirsch, A.

1911. New Paleozoic Insects from the Vicinity of Mazon Creek, Illinois. Amer. Journ. Sci. (4) 31: 297-378.

Rolfe, W. D. I.

1967. Roclidalia, a Carboniferous Insect Nymph. Paleont. 10(2) : 307313. 


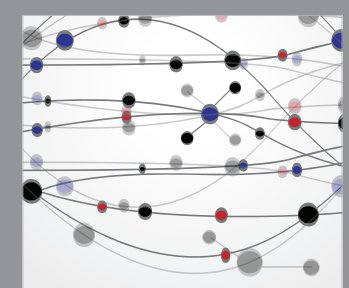

The Scientific World Journal
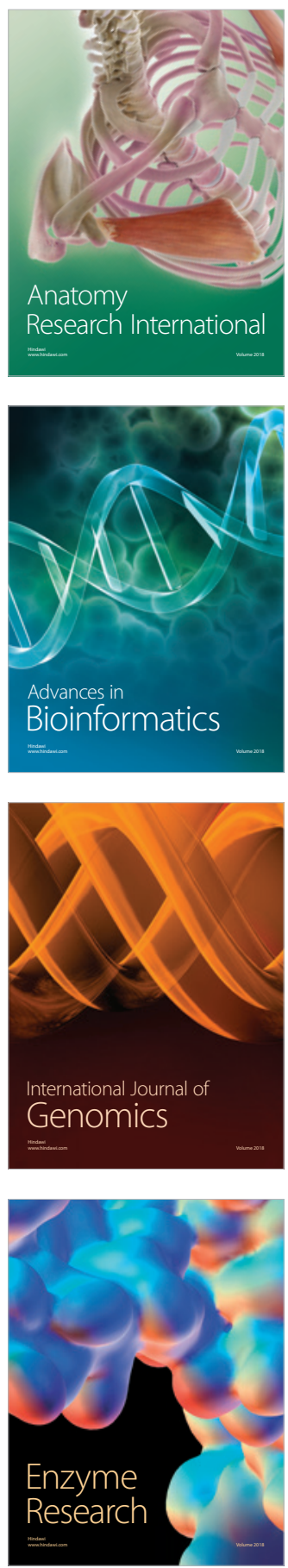
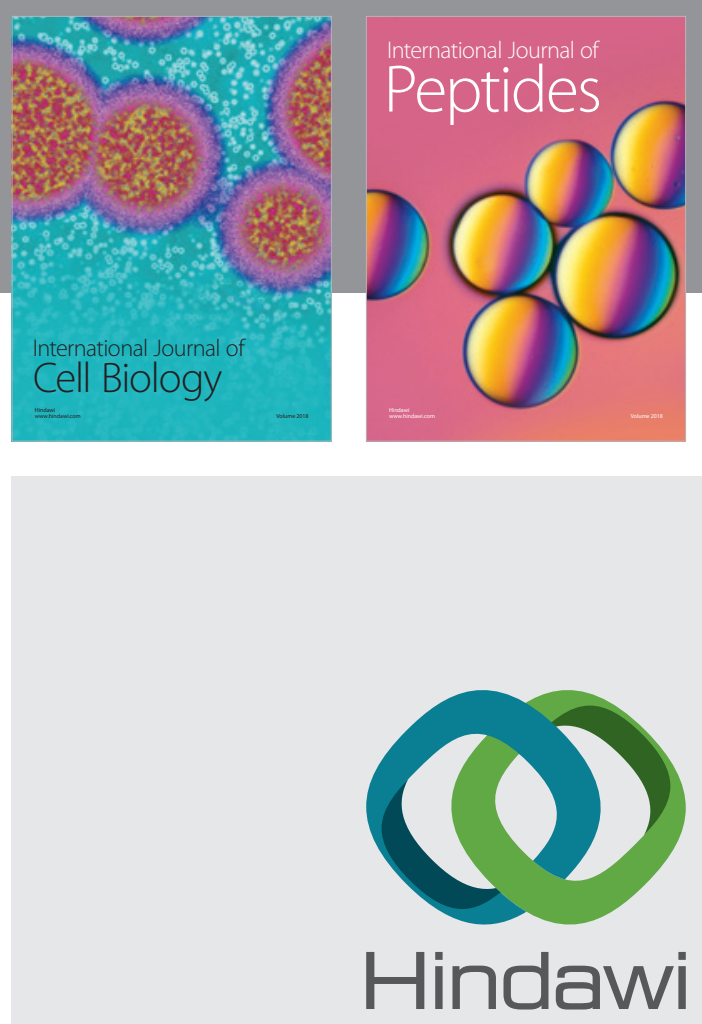

Submit your manuscripts at

www.hindawi.com
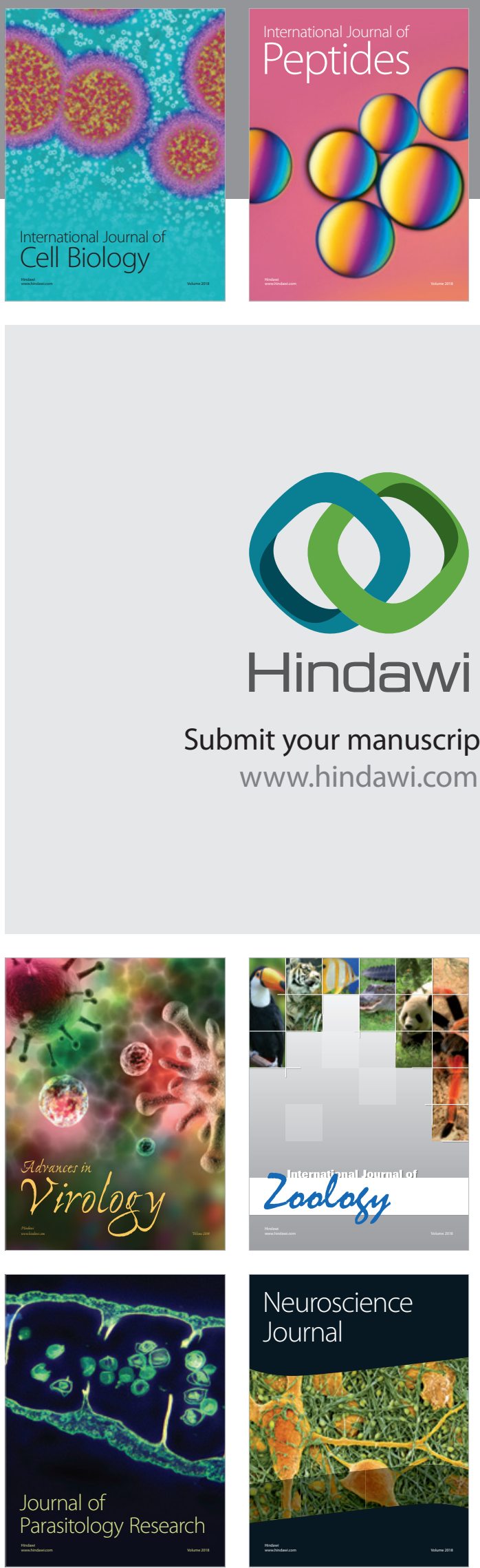
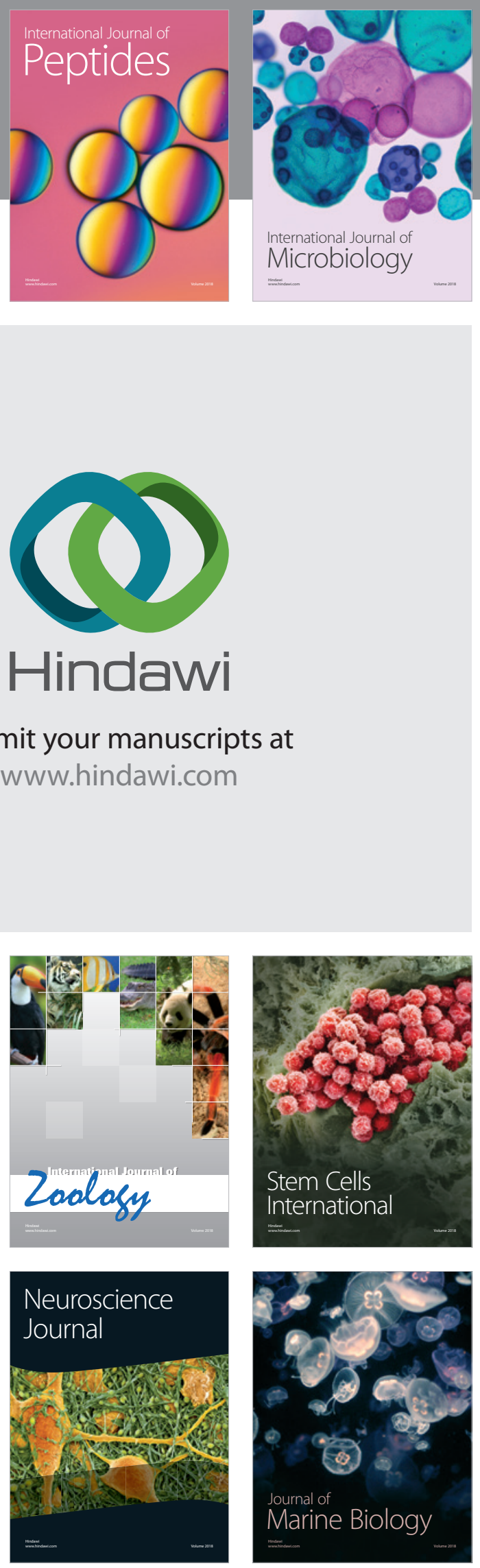
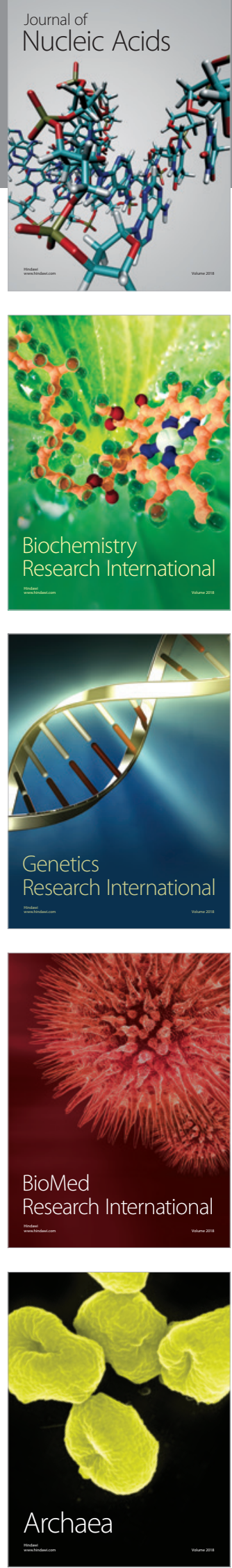